\title{
Henry Colecraft
}

\author{
A soccer striker and his ion channel rescue tools.
}

I/ got into science because I was interested in understanding how things worked at a very fundamental level," says Henry Colecraft, a researcher at Columbia University College of

Physicians and Surgeons and vice-chair of the Department of Physiology and Cellular Biophysics. Over time, he added techniques for exploring mechanisms and ways of translating findings. "The best projects, the ones that make me most excited, have all three elements to it: something that's mechanistic, I can make a new tool and it can have a practical application."

These aspects hold true for his lab's new tools called enDUBs: YFP-targeted engineered deubiquitinases, in which the catalytic domain of a deubiquitinase is fused to a nanobody specific for the fluorophores GFP and YFP. These are ubiquitin scrubbers and ion channel rescue tools of sorts. A patent is pending for enDUBs, and a startup is in the making.

Ubiquitin, as the name suggests, is everywhere in eukaryotic cells. When ubiquitin latches onto a protein, the protein is marked for recycling in the proteasome. Considering how ubiquitous ubiquitination is, "I've been really amazed about what is not known," says Colecraft.

It's known that ubiquitin regulates ion channels, which are protein complexes that are embedded in the cell membrane and through which ions flow into or out of a cell. The Colecraft lab has long studied these ion channels and, for example, developed a targeted ubiquitin ligase that adds ubiquitin to such channels. Scott Kanner, a MD/PhD student who is about to defend his thesis, has been working on this project; it has been ever-expanding as the lab explores these channels.

Some ion channels are selective for a particular ion type. In a heart condition called long QT syndrome, potassium ion channels do not work well. This disturbs the rhythm of heart muscle cell contraction and relaxation, and can be deadly. Each heartbeat starts with an electrical spark from pacemaker cells that ignites an electrical wave and spreads through the heart. Ion channels open and close and act as a conduit for this wave.

Ion channel deficits play a role in long QT syndrome, as well as some types of epilepsy, cystic fibrosis and diabetes.

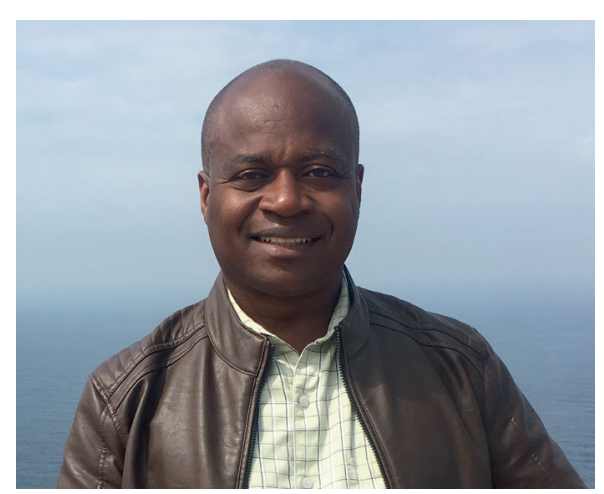

Henry Colecraft

In some cases, the ion channel proteins get stuck inside the cell, unable to do their jobs at the cell surface, which leads to pathology, says Colecraft. Defective ion channels, the team noticed, have a lot of ubiquitin on them. Mutations affect ubiquitination and disrupt ion channel trafficking.

Instead of using their approach to add ubiquitin to ion channels, says Colecraft, in a journal club meeting the idea emerged to remove ubiquitin. "As Scott was talking about this data, you know, someone suggested, 'Oh, could this be applied to ion channelopathies?"' says Colecraft.

"It's an obvious question, once you ask it." Experiments revealed that ubiquitin removal could 'rescue' the ion channel and restore function. "It's a wonderful way of looking at a lab dynamic and how different people see different things and then apply it to a story," he says.

The way enDUBs remove ubiquitin in a targeted way makes the tools usable on many types of ion channels with disrupted ion channel trafficking. "It's totally generalizable," says Colecraft. They showed that enDUBs work in two quite dissimilar ion channels in two different organs, one related to long QT syndrome and the other to cystic fibrosis. Given that ubiquitin is everywhere, says Colecraft, whenever you wish to stabilize a protein, ubiquitin is likely to be involved. It's why he hopes enDUBs will be useful to many labs.

"Colecraft is originally from Ghana in West Africa. Colecraft's father did his graduate work in Boston and took the family along. When Colecraft was a teenager, the family moved to England, where he completed secondary school and his first degree at the University of London's King's College. He went on to complete his $\mathrm{PhD}$ research in pharmacology at the University of Rochester in New York. He spent his postdoctoral years at Johns Hopkins University School of Medicine, where he was recruited as faculty.

When he arrived to give an invited talk at Columbia University, he was greeted with a surprise from the department chair. "The first sentence he said was: 'we are trying to recruit you here'” says Colecraft. To him, this shows leadership committed to diversity from someone who "really walks the walk and not just talks about it."

Dan Minor, a biophysicist at the University of California San Francisco, calls his friend and colleague Colecraft an outstanding scientist and a first-rate ion channel biophysicist who also finds creative ways to control channel function. "Henry has an unflappable character that exudes calmness, kindness and a spirt of generosity that is inspiring to his friends and trainees," says Minor.

\section{"I see myself as helping them reach where their potential is."}

Colecraft feels close to his global community of colleagues and misses traveling to see them as a result of COVID-19. When possible, he enjoys outdoor activities such as hiking. He also plays soccer, which he has done since boyhood. "I've always been a striker," he says. Being a striker, or forward, is about seizing opportunity. He mentors his trainees in this vein, teaching them to watch for opportunities. But he mentors in ways specific to each person. "I see myself as helping them reach where their potential is."

\section{Vivien Marx}

Published online: 18 November 2020 https://doi.org/10.1038/s41592-020-01012-3

Reference

Kanner, S. et al. Targeted deubiquitination rescues distinct trafficking-deficient ion channelopathies Nat. Methods https://doi.org/10.1038/s41592-02000992-6 (2020). 